\title{
IT /IS Outsourcing from Omani Organizations' Perspective: Motivations and Reservations
}

\author{
Khamis Al-Gharbi (Corresponding author) \\ Sultan Qaboos University, Al-Khod, Sultanate of Oman \\ E-mail: algharbi@squ.edu.om \\ Ahmed Al-Kindi \\ Sultan Qaboos University, Al-Khod, Sultanate of Oman \\ E-mail: ahmed@squ.edu.om \\ Zahran Al-Salti \\ Sultan Qaboos University, Al-Khod, Sultanate of Oman \\ E-mail: zahrans@squ.edu.om
}

\begin{abstract}
In recent years outsourcing has become one of the strategies pursued by organizations in order to manage their Information Technology/ Information Systems (IT/IS) (Gonzalez et al., 2006).Organizations turn to outsource their IT/IS for a number of reasons. Many Omani organizations outsourced part or all of their IT/IS while others are conservative and following 'wait and see' strategy. The aim of this paper is to explore the main motivations for or against outsourcing IS/IT within the Omani private and public sectors. With this aim in mind, a questionnaire survey was used as the main method to collect data from Omani private and public organizations. In addition two semi structured interviews were conducted to detect some issues that were not possible otherwise. The results of the analysis of the data show that the main drive behind IS/IT outsourcing is the need to obtain the required skills which are not available otherwise. The study also shows that security issues and concerns are among the top reasons preventing some Omani organizations from outsourcing.
\end{abstract}

Keywords: IT/IS Outsourcing, Private sector, Public sector, Oman 


\section{Introduction}

Many organizations nowadays rely more and more on IT/IS to manage their business, however some of them found it uneasy to develop, control and maintain IT/IS functions. Therefore, many organizations have transferred the IT/IS responsibility to a specialized third-party vendor, focusing on the right resources and activities needed for the core business.

Information Technology / Information Systems (IT/IS) outsourcing has become an important issue for many organizations for different reasons. Some companies seek to outsource for tactical reasons while others for strategic reasons.

Many organizations tend to separate the support functions from the core activities of their businesses. They find it more effective and efficient to focus on the business's core competencies and to outsource the support tasks to a highly specialized third party vendor. IT/IS has been considered as one of the leading areas of outsourcing. Organizations are seeking to contract with outside vendors to provide them predetermined IT services at predetermined prices over agreed upon period of time.

IT/IS Outsourcing has been growing at accelerating rate over the past five years, with global market over \$ 100 billion annually (Cullen, Willcoks, and Seddon 2001; Dennis, Wixom, and Roth 2006). Gartner Group cited in Gonzalez et al, (2006) has estimated global IT outsourcing market to be over $\$ 253$ billion in 2008. Organizations in developed countries are spending an average of $30 \%$ of their IT budgets on outsourcing (Cullen, Willcoks, and Seddon 2001). Lacity and Willcocks (2001) attributed the growth of IS outsourcing market to two main phenomena. The first one there is a change in business strategy. Organization leaders have realized that in order to achieve sustainable competitive advantage it is necessary to abandoned diversification strategy and focus on core competencies while outsource the rest (Dibbern et al., 2004). The second reason for growth of IS outsourcing is the perception that IS internal department is a cost burden that should be reduced and the growth of outsourcing is a function of unclear value delivered locally (Dibbern et al., 2004. Many organizations are looking toward outsourcing as standard management tool that can help them to achieve many objectives.

The purpose of the paper is to explore the main reasons for or against outsourcing IS/IT within the Omani organizations context. The questions this paper is trying to address are: Why Omani organizations are outsourcing their IT/IS functions?. Why some Omani organizations are not outsourcing? It also identifies the most common challenges, obstacles and concerns when outsourcing IT/IS.

\section{Definition and Types of IT/IS Outsourcing}

IS/IT outsourcing is defined as the process in which an organization turns out all or part of it functions to an outside vendor. Cheon et al. (1995, p. 209), define IS/IT outsourcing as "the organisational decision to turn over part or all of an organisation's IS functions to external services provider(s) in order for an organisation to be able to achieve its goals. This definition includes the following external services: applications development and maintenance, systems operations, network/communications management, end-user computing support, systems 
planning and management, and purchase of application software, but excludes business consulting services, after-sale vendors' services, and the lease of telephones lines. An organization can obtain these services through complete outsourcing, facilities management, systems integration, time-sharing, and other contracts (including rental, installation and procurement, and maintenance and programming”. Lacity and Hirschheim (1995) identified three strategic options available to organizations. There options are: Total insourcing which means that the organization retains the management and the provision of more than $80 \%$ of IS budget internally. Selective IT/IS outsourcing is the process of outsourcing a selected IT functions to an external specialized vendor (s) while still providing between $20 \%$ and $80 \%$ of the IT/IS budget internally (Lacity \& Willcocks, 1998). The above percentage for selective outsourcing of IT budget is slightly different from Willcocks and Fitzgerald(2004) which shows that selective outsourcing takes between 25 to $40 \%$ of IS budget. Total IT/IS outsourcing which is considered the most comprehensive types 0is categorized by transferring the responsibility of IS assets, leases, staff and management, an equivalent of more than $80 \%$ of the IT budget to an external service provider (s) (Lacity \& Willcocks, 1998; Lee, et al, 2000).

\section{Main Drives for IT/IS Outsourcing}

Outsourcing IT/IS has become an important issue for many organizations for different reasons and the most important is cost reduction (Susarla et al., 2003). Costa (2001) has identified three driving forces for IT/IS outsourcing. These are: Cost reduction, technical consideration and the need to focus on core competencies of the business. The three driving forces are discussed in details in the following sections.

\section{Cost Reduction}

The growing pressure to reduce cost and improve efficiency encourages many organizations to outsource part or all of their IT/IS. Cost reduction is the most frequently cited factor in the IT/IS outsourcing literature. Many organizations worldwide outsourced part or all of their IT/IS functions in order to reduce costs of manpower, supplies and maintenance (Aalders 2002). There is a strong believe that IT vendors possess economies of a scale and technical expertise in comparison to IS internal departments and therefore can provide IS services more efficiently (Dibbern et al., 2004). Papp (2003) agues that cost reduction is a key factor in the decision to outsource. Collins and Millen (1996) carried out a comprehensive study to provide information about outsourcing IT/IS in the United States. They found out that cost savings resulting from a reduction of personal were the main reason for IT/IS outsourcing. Cost saving may give the company a competitive advantages.

\section{Technical Skills and Resources}

Traditionally one of the main driver for IT/IS outsourcing is cost reduction. However, recently the decision to IT/ IS outsourcing has moved from tactical (cost reduction) to strategic decision. The key driver for outsourcing is to obtain IS skills and expertise which is not available internally and through this strategy organizations can gain competitive advantage( Teng et al., 1995; Yan and Huuang, 2002). 
Edguer and Pervan ( 2002) argued that a shortage of skilled IS professionals places pressure on IS managers to select outsourcing strategy in order deliver on their promise of faster, cheaper and better solutions. In a survey conducted in Australia in the year 2000, found that $60 \%$ of the participants cited "access to skills / expertise” is the main drive for outsourcing (Cullen, Willcoks, and Seddon 2001).

\section{Focus on core competencies of the business}

Traditionally organizations have used diversification strategies in order to minimized risk, however; recently this philosophy has been abandoned. Core competencies theory suggests activities should be performed either in-house or by outsider vendors. Activities which are not core competencies should be considered for outsourcing (Quinn, 1992). Many organizations tend nowadays to outsource non-core competencies, while focusing on core business activities. This strategy concentrates on what organization does better while outsourcing the rest (Dibbern et al., 2004). Outsourcing vendors generally promise to manage the functions that cannot add value internally, freeing up management time to focus on central strategic business issues (Caldwell and McGee, 1998). Beaumont and Sohal (2004) stressed that managers should apply their experience and knowledge to core competencies and outsource activities in which they are less competent and can benefit from vendors' expertise.

\section{Reasons against outsourcing}

Some organizations are very conservative and extremely cautious toward outsourcing for many reasons. Tafti(2005) warns organization from some risks in the areas of individual privacy, data security and loss of IT expertise associated with IT outsourcing. One of the vital risks associated with outsourcing is losing a significant portion of company IT talent and expertise. This can cause devastating effect on future ability to lean (Perrons and Platts, 2004).

Other researchers and scholars like (Cullen, Willcoks, and Seddon 2001; Laudon and Laudon 2003; Earl and Sampler 1998)

have warn from other types of risks associated with IT/IS outsourcing, such as the risk of loss of control; fear of loss of organizational knowledge; cost and complexity of the outsourcing process; risk of losing internal expertise and most importantly, concerns towards security and confidentiality issues where IT is deemed too strategic to put in the hands of others.

According to Earl and Sampler (1998) not all organizations benefit from outsourcing deal, and the disadvantages of outsourcing can create serious problems for organizations if it is not understood and managed. Furthermore, the hidden cost of outsourcing which cannot be seen upfront can swallow any anticipated benefits from it.

\section{Research Methodology}

Questionnaire survey is the main method used to collect data from private and public organizations in Oman. In addition to the questionnaire two semi-structured interviews were conducted with two IT directors representing private and public sectors to detected issues that were not possible by the questionnaire. 
Questionnaire was used as the main method to collect data due to the following reasons:

- The ability to detect relationships that are common across the organizations and hence to provide generalisable statements about the object under study (Gable, 1994).

- It exhibits considerable precision in collecting and reporting data (Bryman, 1996; Ganzalez, 1998; Remenyi and Williams, 1995).

- It is considered to be an inexpensive approach to gather data (Remenyi and Williams, 1995).

- It generally offers the anonymity that may lead participants to be more open and truthful (Al-Assaf, 1997; Al-Shuabi, 1991).

- The use of the questionnaire also has advantage of overcoming many cultural factors. For example, it is part of the Arab culture that personal and family or business information should not be discussed outside the boundaries of the family or the company as such matters are viewed as being very private (AL-Qahtany, 1996).

The respondents to questionnaire, therefore, may hold greater credibility, as participants do not have to identify themselves or their organizations. This can explained why this research opts for the use of questionnaire survey as the main data collection method.

Questionnaires were sent to 100 private and public organizations selected randomly. 40 questionnaires were returned, where the data shows that 23 of the 40 (about 56\%) of organizations surveyed have outsourced some of their IS/IT functions. Forty three percent (43\%) of those companies that have outsourced are public organizations. Sixty percent (60\%) of those that not outsourced are public organizations.

The size of the organizations surveyed varies from small to large. Twenty four percent of the organizations are small (less than 100 employees). Thirty four percent of the organizations are medium size (100 to 999 employees). The rest are large (more than 1000 employees).

\section{Main Findings from the Questionnaire}

\subsection{Reasons for outsourcing}

Figure 1 shows that the main motive for Omani organizations to outsource IS/IT is to obtain skills and expertise. This is due to the fact that many Omani organizations lack qualified IT professionals who are capable of building reliable and robust applications in a reasonable time. This finding represents a significant difference from the previously mentioned literature (see, for example, Collins and Millen (1996), Aalders (2002), and Papp (2003), which states that the number one motive for outsourcing is cost reduction). Figure 1 reveals that cost saving is the fourth reason for outsourcing within Omani organizations. This can be explained by the reality (fact) that organizations in some developing countries have a sever shortage of skilled IT professionals. Therefore their main motive from outsourcing deal is not a tactical decision (cost reduction) but a strategic decision and necessity. Figure 1 also indicates that focusing on the core business of the organization is the second important reason. This strategy means that Omani organizations put their emphasis on the core business while 
leaving matters that are considered not strategic to external providers. Outsourcing vendors generally promise to manage the functions that cannot add value internally, freeing up management time to focus on strategic issues. Access to better technology is the third drive that has led Omani organizations to outsourcing part or all of their IT/IS functions. This strategy offers an opportunity for Omani organizations to obtain a better and a new cutting-edge technology which may be difficult to get otherwise. The last reason for outsourcing with the context of Omani organizations is to achieve quality improvement and only a few organizations have selected it as the driver for outsourcing. One may say that quality improvement is not strong drive to be achieved via outsourcing deal but we csan argue that the priority here it to obtain professional IT skilled which the organizations are in great need and consequently the quality will improve considerably.

\subsection{Reasons against outsourcing}

Figure 2 shows security concern is the main reason preventing many Omani organizations in both private and public sectors from outsourcing their IT/IS functions. The core issues of security include data confidentiality, privacy, authority and accountability. Security concern is the key factor prevents top management from relying on outside vendors to build or maintain very important and sensitive applications. In addition, the risk of loosing control of vital applications to outside vendors explains the cautious approach of many Omani organizations towards outsourcing. Furthermore, the belief that IS/IT is too strategic that should not be outsourced to outsider adds to the concerns of conservative organizations. These findings, as well as the cost and complexity of the outsourcing process, are deemed to be the main reasons against outsourcing for Omani organizations.

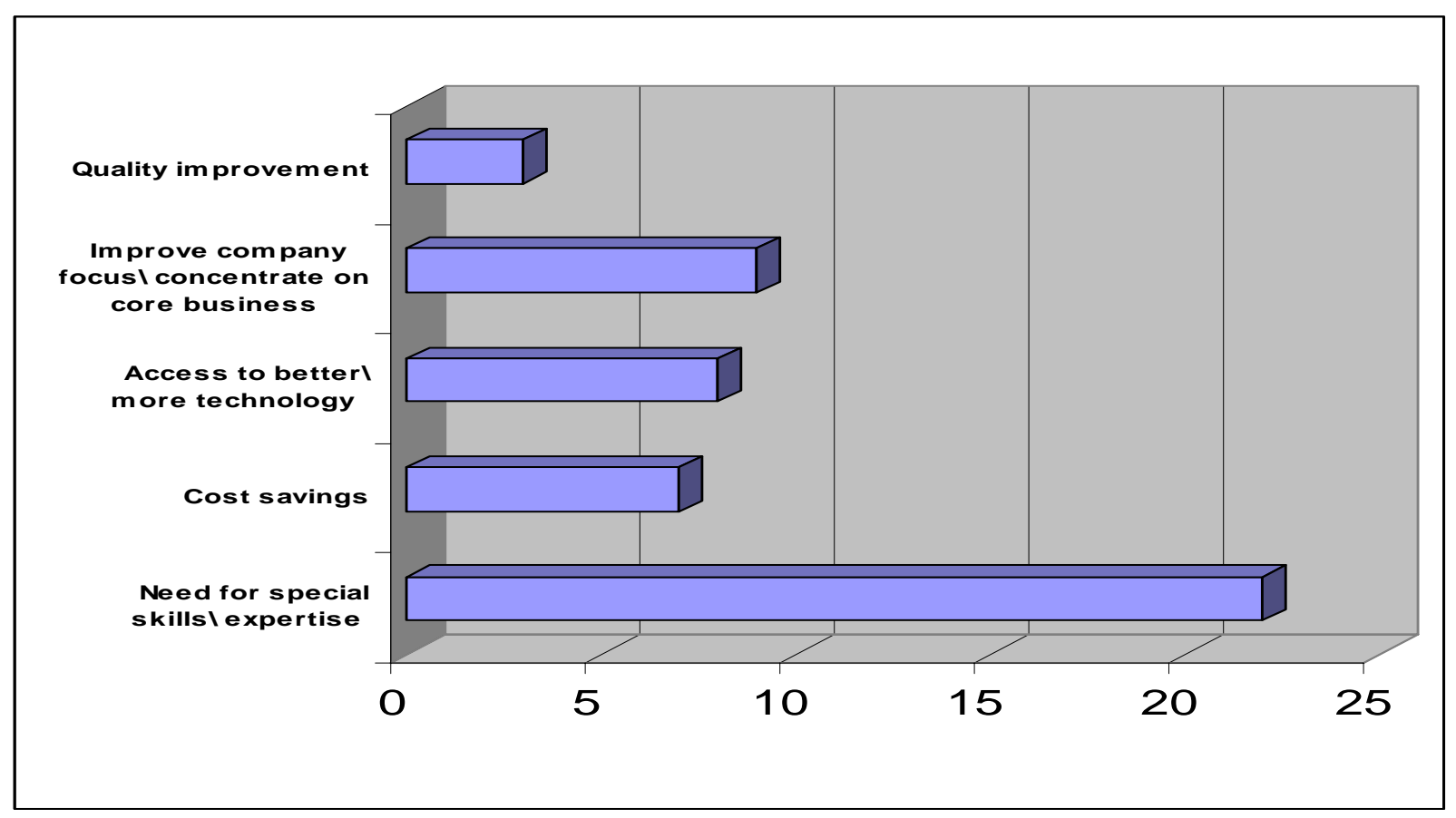

Figure 1: Motives for Omani organizations to outsource IS/IT 


\section{Macrothink}

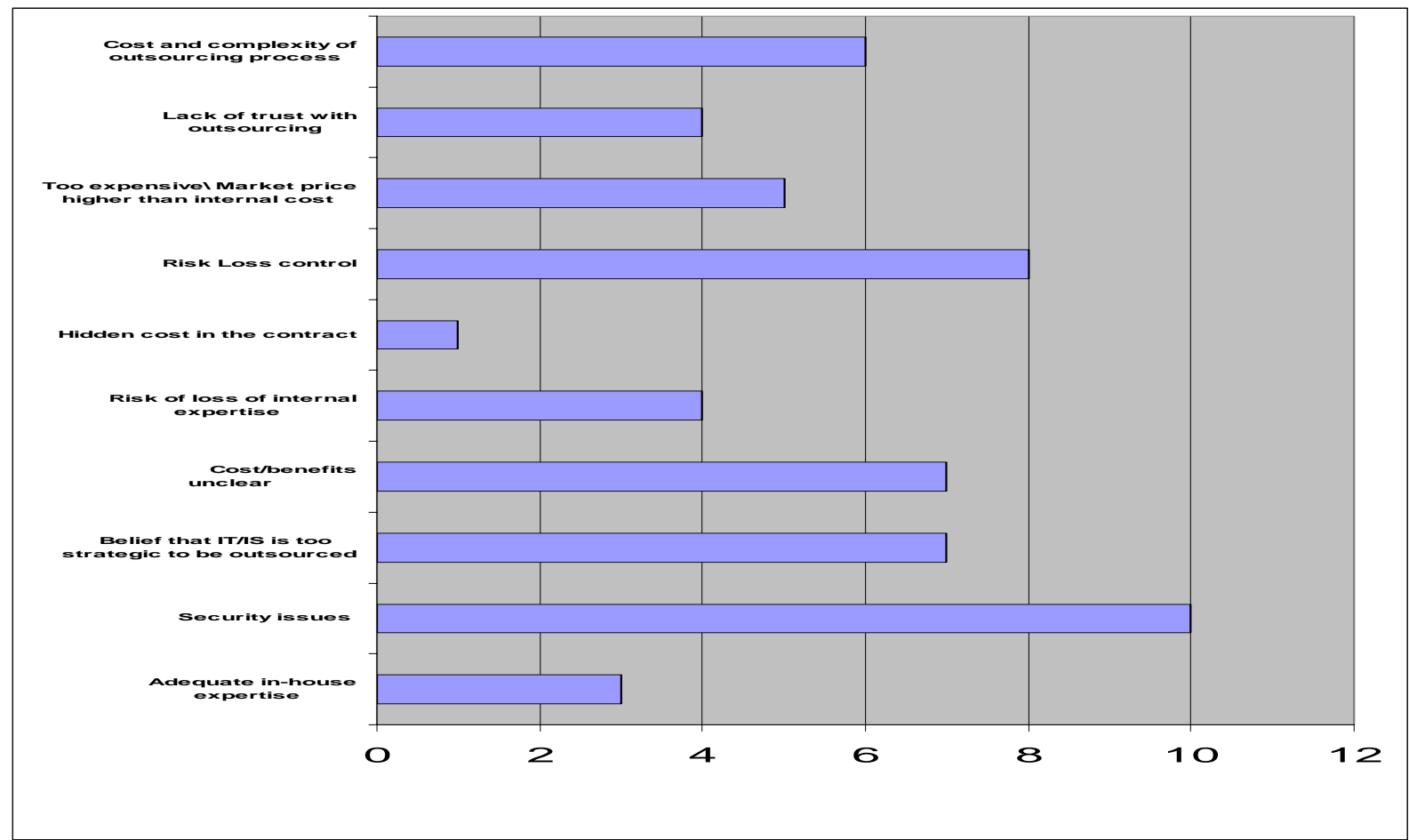

Figure 2: Reasons against outsourcing IS/IT in the context of Omani organizations

\section{Main Findings from the Interviews}

Interviews revealed that the Omani organizations that the researchers investigated is less likely to achieve cost savings and more likely to fill human and IT resource gaps through outsourcing. This is due that many Omani organizations lack of qualified IT professionals capable of building reliable robust applications in reasonable time; providing a sound solutions that that satisfies organizational needs and offering quality services. Therefore, the main motive for Omani organizations for outsourcing is to obtain skills, expertise, service and technology not otherwise available to them in-house. This finding represent a significant different from the previously mentioned literature review (see, for example, Collins and Millen (1996), Aalders (2002), and Papp (2003) ), which stated that the number one motive for IT/IS outsourcing is cost reduction. This significant difference can be interpreted that organizations in some developing countries such as Oman have a severe shortage of skilled IT professionals.

The interviewees also uncovered significant problems that are encountering Omani organizations when outsourcing. Some of the local suppliers are not able to provide the right expertise/skills. This is mainly because of the inability of local suppliers to attract and retain qualified and skilled IT professionals.

Little knowledge transfers from supplier was indicated as one of the challenges that faces clients during the outsourcing process. The interviewees stressed that the value delivered by the supplier in outsourcing contract was seldom satisfactory. Therefore, those interviewed 
organizations spend $10 \%$ only of their IT budget on outsourcing. This is an equivalent of only one third what is usually spent in comparable organization in developed countries. Furthermore, organizations that have outsourced all or part of their IS/IT functions often are unpleasantly surprised to find out at a later stage that their vendors are involved in so many projects at the same time that they can not provide the adequate support promised at the beginning of the contract.

Another concern raised during the interviews is that organizations in Oman in most cases lack the experience and knowledge to write and negotiate a sound contract. As a result, organizations often highly depend on vendors to write the contract which in most cases are in the favor of the vendors. This can cause problems during the execution and the interpretations of the contract which may favor the vendor. It should be noted that the finding from the two semi structured interviews cannot be generalized but it gives indication of the issues and concerns facing some Omani organizations in the public and private sectors.

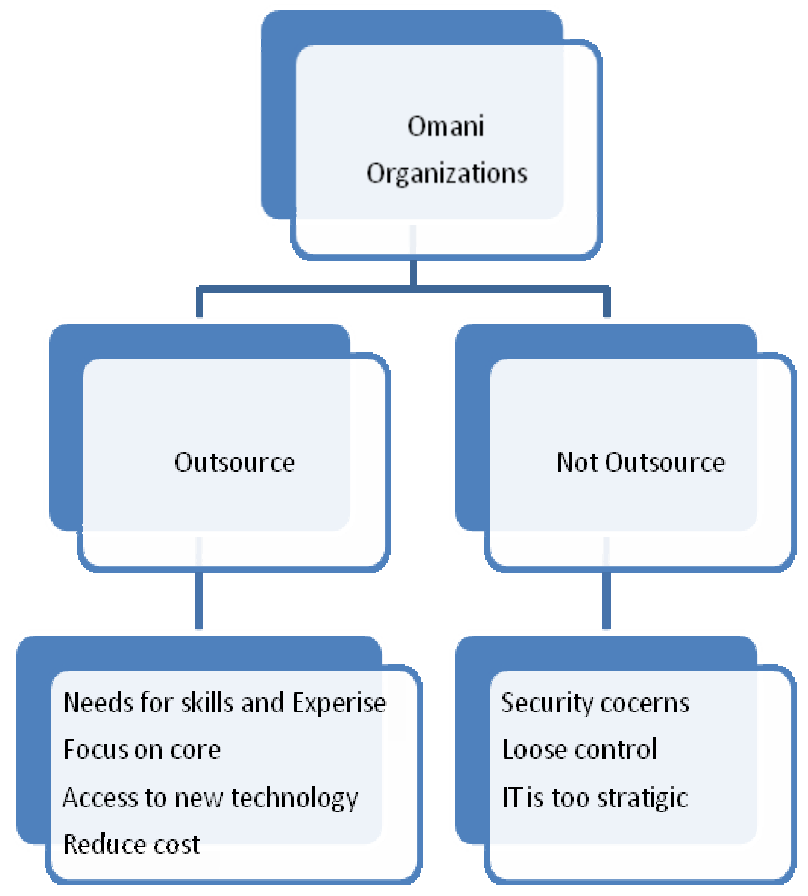

Figure 3: Summarized the main findings

\section{Conclusion}

Many Omani organizations in private and public sectors are engaged in outsourcing their IT/IS functions with various degrees and for many reasons while others are waiting suspiciously toward outsourcing deal.

This paper found that the main motive for IT/IS outsourcing within the Omani organizations context is to obtain skills and expertise. This is due to the fact that many Omani organizations lack qualified IT/IS professionals who are capable of building reliable and robust applications in a reasonable time. The study also showed that the issues of security prevent top management from relying on outside vendors to build or maintain very important and 
sensitive applications.

Whilst organizations in most developed countries are motivated toward outsourcing in order to achieve cost savings. Organizations in Oman are outsourcing their IT/IS function primarily due to lack of experienced and skillful IT professionals.

\section{References}

Aalders, R. (2002), “IT Outsourcing: Making IT Work”, Fujitsu Australia Limited.

AL-Assaf (1997) Computer-Based Information Systems in the Role of Information Technology Manager in Saudi Arabia, Ph.D. Thesis, University of Manchester.

AL-Qahtany, S.(1996) Management Development in Saudi Arabia: The Preparation for Borderless World, Ph.D. Thesis, University of Leicester.

AL-Shoaibi, A.(1998) The Impact of Information Technology on Organisations: The case of Saudi Private Sector, Unpublished Ph.D. Thesis, University of St Andrews.UK.

Bryman, A.(1996)Quantity and Quality in Social Research. Routledge, London.

Burgess, R.G.(1982) Field Research: A Sources Book and Field Manual. London, Allen \& Unwin.

Caldwell, B. and McGee, M. (1998), "Surge in services Year 2000, labor shortages, and profitability goals driver services demand”, InformationWeek, No. 663, pp. 57-62

Collins, J. and Millen, R. (1995), "Information systems outsourcing by large American industrial firms: choices and impacts”, Information Resources Management Journal, vol. 8 No. 1, pp.5-13.

Costa, C. (2001), "Information Technology outsourcing in Australia: a literature review”, Information Management \& Computer Security 9/5 213-224.

Cullen, S., Willcoks, L., and Seddon, P. (2001). "Information Technology Outsourcing Practices in Australia”, Deloitte Touche Tohamatsu.

Dennis,A., Wixom, B., Roth, R. (2006), “System Analysis \& Design”, John Wiley \& Sons.

Earl, M., and Sampler, J. (1998), “Market Management to Transform the IT organizations”, Sloan Management Review,39, No4

Edguer, E. and Pervan, G. (2002), "The success of IS/IT co-sourcing contract arrangement in government agencies”,School of Information systems, Curtin University of Technology

Gable, G. (1994), "Integrating Case Study and Survey Research Methods: an Example in Information Systems”, European Journal of Information Systems, 3, No. 2, pp. 112-126.

Gonzalez, J.S. (1998) The 21st- Century Intranet, Prentice-Hall, Inc, NJ.

Gonzalez, R., Gasco,J. and Llopis,J.(2006) "Information systems outsourcing: A literature analysis ", Information \& Management 43,pp.821-834. 


\section{Macrothink

Khalfan, A. and Alshawaf, A. (2003), "IS/IT outsourcing practices in public health sector of Kuwait”, Logistic Information Management Volume 16, Number 3/4 pp. 215-228

Lacity, M. and Willcocks, L. (1998) “An empirical investigation of information technology outsourcing practices: Lessons from experience”, MIS Quarterly, 22(3), pp. 364-408.

Laudon, K. ,and Laudon, P.(2003), “Essentials of Management Information Systems” Prentice-Hall,New Jersey.

Lee, J., Huynh, M., Chi-wai, K. and Pi, S. (2000) “The Evolution of Outsourcing Research: What is the next issue?" Proceedings of the 33rd Hawaii International Conference on Systems Sciences.

Leidner, D. and Jarvenpaa, S. (1993), “The information Age Confronts Education: Case studies on Electronic Classrooms”, Information Systems Research, 4(1), 24-54.

Northfield, D. (1992), “ Outsourcing of IT Services: Case study of the contract between the Tricontinental Royal Commission and ICL Australia Ltd, CIRCIT

Papp, A. (2003), “Outsourcing Systems Management”, Hershey, PA: Idea Group Publishing.

Perros, R.K. and Platts, K.(2004). "The role of clockspeed in outsourcing decisions for new technologies: insight from the prisoner's dilemma", Industrial Management \& Data systems, Vol.104, No.7, pp.624-632.

Quinn, J.B.,(1992) ."Intelligent Enterprise: Free press, New York.

Remenyi, D. (1996) Ten Common Information Systems Mistakes, Journal of General Management, Vol.21, No.4, pp.78-91.

Remenyi, D and Williams, B. (1995) Some aspects of methodology for research in information systems. Journal of Information Technology, Vol. 10, pp.191-201.

Susarla, A., Barua, A. and Whinston, A.B.(2003)"Understanding the service component of application service provisions: an empirical analysis of satisfaction with ASP services", MIS Quarterly, Vol.27 No.1,pp.91-123.

Tafti, Mohammed,H.A (2005). Risk factors associated with offshore IT outsourcing, Industrial Management \& Data systems, Vol.105, No.5, pp.549-560.

Willcocks, L. and Fitzgerald,G.(2004) A Business Guide to Outsourcing Information Technology, London: Business Intelligence.

Yin, R. (1994), “Case Study Research Design and Methods”, 2nd ed. Newbury Park, Sage Publications. 